\title{
Transition Metal-mediated Reactions in Biological Media
}

\author{
Miguel Martínez-Calvo* and José L. Mascareñas*
}

\begin{abstract}
Transition-metal catalysis has changed the way in which chemical reactions can be accomplished. While most metal-catalyzed reactions have been achieved in organic solvents, recent work has demonstrated that many of these transformations can be made compatible with water. These discoveries have stimulated the search for metal catalysts that are capable of achieving designed reactions in biological settings, and eventually behave as non-natural enzymes working in native cellular environments. Although this new field of research is still taking its first steps, there is a growing number of publications in the area, and one can predict that it will steadily grow in the years to come. Here we will briefly review some of the main contributions in the area. The contents have been organized according to the type of transformation and transition metal catalysts involved in the process.
\end{abstract}

Keywords: Artificial metalloenzymes · Bioorthogonal · Living cells · Organometallic · Transition metal catalysis

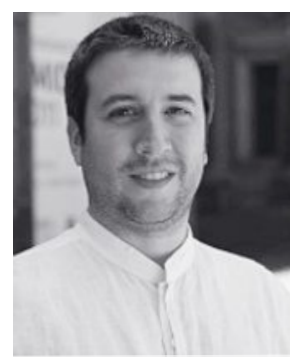

\section{Dr. Miguel}

Martínez-Calvo

did his $\mathrm{PhD}$ at

the University of

Santiago de Compostela under the supervision of Prof. Manuel R. Bermejo working in the field of coordination and supramolecular chemistry. He carried out two predoctoral stays at University of Pavia (Italy) under the supervision of Prof. Luigi Fabbrizzi and Prof. Luigi Casella. After receiving his $\mathrm{PhD}$, he was awarded with a fellowship to join Prof. Thorri Gunnlaugsson in Trinity College Dublin (Republic of Ireland) carrying out studies on $\mathrm{Ru}(\mathrm{II})$ polypyridyl complexes tethered onto AuNP and their interaction with DNA, Lanthanides supramolecular self-assembly. Later he was awarded a 'Juan de la Cierva' fellowship to join Prof. José Luis Mascareñas group for the development of transition metal catalysts capable of retaining their transformative power in living cells.

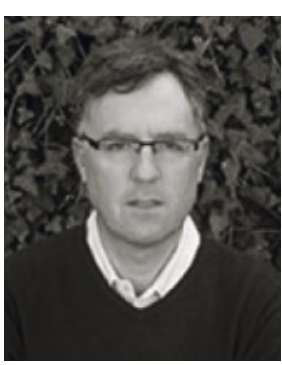

Prof. José Luis Mascareñas completed his $\mathrm{PhD}$ at the University of Santiago in 1988. $\mathrm{He}$ was a postdoctoral fellow at Stanford University (USA) under the supervision of Prof. Paul Wender (1989-1990); and became permanent professor in 1993, and full professor in 2005, at the University of Santiago. He has been visiting scholar at Harvard University (USA) in the summers of 1992 and 1995 and visiting scientist at University of Cambridge (UK, 2009) and MIT (USA, 2013). In 2009 he received the Organic Chemistry award of the Spanish Royal Society of Chemistry. In 2014 he received the advanced grant ERC award of the EU, in 2015 the Gold Medal of the Spanish Royal Society of Chemistry and in 2016 was elected as member of the EURASC. His current research ranges from the discovery and invention of new metal-catalyzed processes to chem-bio programs aimed at designing new nucleic acid binding tactics, as well as at devising artificial catalysts that work in biological settings.

\section{Introduction}

Translating metal-catalyzed reactions

${ }^{*}$ Correspondence: Dr. M. Martinez-Calvo, Prof. J. L. Mascareñas

E-mail: miguel.martinez@usc.es,

joseluis.mascarenas@usc.es

Centro Singular de Investigación en Química

Biolóxica e Materiais Moleculares (CIQUS)

Departamento de Química Orgánica, Universidade de Santiago de Compostela,

15782 Santiago de Compostela, Spain to biological settings is extremely challenging due to the aqueous environment, and to the presence of a high concentration of biomolecules such as thiols or amines which can poison the metal and kill its catalytic activity. In the case of reactions in living cells, additional issues such as toxicity of the metals and cellular transport must also be taken into account. Despite these challenges, there have been an increasing number of reports on the use of metal-based catalysts in aqueous buffers, biological media and even in vivo settings. The viability of promoting non-natural transformations in such environments can have profound implications in biological and medicinal research, both in terms of advancing basic knowledge as well as of discovering new therapeutic or diagnosis strategies..$^{[1-4]}$

A key development that triggered this field of research at the boundary between metal catalysis and chemical biology was the discovery of the Copper-Catalyzed Azide-Alkyne Cycloaddition $(\boldsymbol{C u A A C})$ by the groups of Sharpless and Meldal. ${ }^{[5,6]}$ The water compatibility and excellent orthogonality of this annulation prompted the development of many applications in biological chemistry, many related with designed modification of sugars ${ }^{[7-9]}$ and proteins on cellular surfaces. ${ }^{[10]}$ This annulation, together with the Staudinger reaction, were the first to be included in the new research area coined as Bioorthogonal Chemistry. ${ }^{[11,12]}$

After these developments, there have been many attempts to discover other orthogonal and biocompatible transitionmetal promoted reactions, however the success has been fairly limited. Davis, Lin and others have demonstrated the viability of using Pd-catalyzed coupling reactions for protein modification in biological compatible media, and even on the surface of bacteria. ${ }^{[13-15]}$ Moving this chemistry to mammalian living cells has been specially challenging, owing to the intermolecular 
nature of the reaction, and because the palladium reagents can be readily deactivated in presence of a relatively high concentration of biomolecules such as thiols and amines. Nevertheless, Unciti-Bruceta and Bradley have reported the use of supported $\operatorname{Pd}(0)$ nanoparticles to promote SuzukiMiyaura cross coupling reactions in living cells. ${ }^{[16]}$ These authors also demonstrated that the palladium nanoparticles can be used to remove allylcarbamate groups in different type of substrates. The group of $\mathrm{P}$. R. Chen has also employed commercially available $\mathrm{Pd}(\mathrm{II})$ and $\mathrm{Pd}(0)$ complexes for the uncaging of propargylcarbamate protected amines groups of proteins involved in the cell metabolism, ${ }^{[17]}$ and more recently, Weisleder and coworkers have also used nanoprotected forms of palladium complexes to achieve similar deprotection reactions within living mammalian cells. ${ }^{[18]}$ While all these examples involve the use of palladium, a seminal report in this topic was published more than ten years ago by E. Meggers and coworkers and dealt with related uncaging reactions promoted by $\mathrm{Ru}(\mathrm{II})$ complexes. [19]

In this short review, we will make a compilation of some of the more remarkable results in this emerging research field devoted to the development of abiotic metal-promoted processes in living environments. The contents of the review have been organized according to the type of chemical transformation that can be achieved, and the main metals that have been used.[20-25] Of course, we do not intend to be comprehensive, and therefore we apologize for not citing all the references to work that has been published in the field.

\section{Bond-forming Reactions}

\subsection{Annulations}

Although annulations do not appear to be the simplest reactions to be achievable in complex aqueous media, the groundbreaking discovery of the bioorthogonal CuAAC triggered a substantial research effort in the area.

\subsubsection{Copper}

Modification of proteins. After the discovery that copper (I) salts or complexes can catalyze the annulation between azides and alkynes in water, there have been many reports trying to exploit this reaction $(\boldsymbol{C u A A C})$ in bio-related research. ${ }^{[5,6]}$ However, the well-known toxicity of copper and the need to use non-innocent reducing agents like ascorbate for the in situ generation of $\mathrm{Cu}(\mathrm{I})$, has limited their use in living environments. [26]

Pioneering work on the use of the $\boldsymbol{C u A A C}$ in biological settings was carried out by D. A. Tirrell and co-workers who reported several $\mathrm{Cu}$ (II) and $\mathrm{Cu}$ (I) complexes able to promote the covalent labelling of cell surface proteins of $E$. coli equipped with azide-modified amino acids. They also showed that the metabolic incorporation of a homopropargylglycine residue provides for a subsequent copper-promoted annulation with 3-azido-7-hydroxycoumarin, which allowed to visualize and monitor the proteins in fixed mammalian cells. [27-29]

The group of P. R. Chen has used the $\boldsymbol{C U A A C}$ reaction for the modification of a periplasmic $\mathrm{pH}$-responsive acidchaperone $H d e A$ in $E$. coli. with a naphthalimide dye (4- $N, N$-dimethylamino- 1,8 naphthalimide). ${ }^{[30]}$ They later showed that with appropriate copper ligands it is also possible to achieve the reaction in the cytoplasm of the bacteria (Fig. 1). ${ }^{[31]}$
Annulation of exogenous small molecules. Promoting the $\boldsymbol{C u A A C}$ of small molecules inside living environments is especially challenging, owing to the entropic difficulties associated with the bimolecular process.

The first example of the use of a copper complex to promote a click-type annulation of small molecules inside living cells was reported by Taran et al. in 2014. Following the copper-chelate concept devised by A. Ting, ${ }^{[10]}$ they designed azides bearing copper-chelating bis(triazole) moieties, and demonstrated that they present good kinetics in the annulation with alkynes (Scheme 1a). This allowed reactions to be carried out under diluted conditions in complex aqueous media, and even inside HUH-7 cells. ${ }^{[33]}$

In 2016, the group of Zimmerman demonstrated that $\mathrm{Cu}$-containing organic nanoparticles (Cu-MONPs) are able to

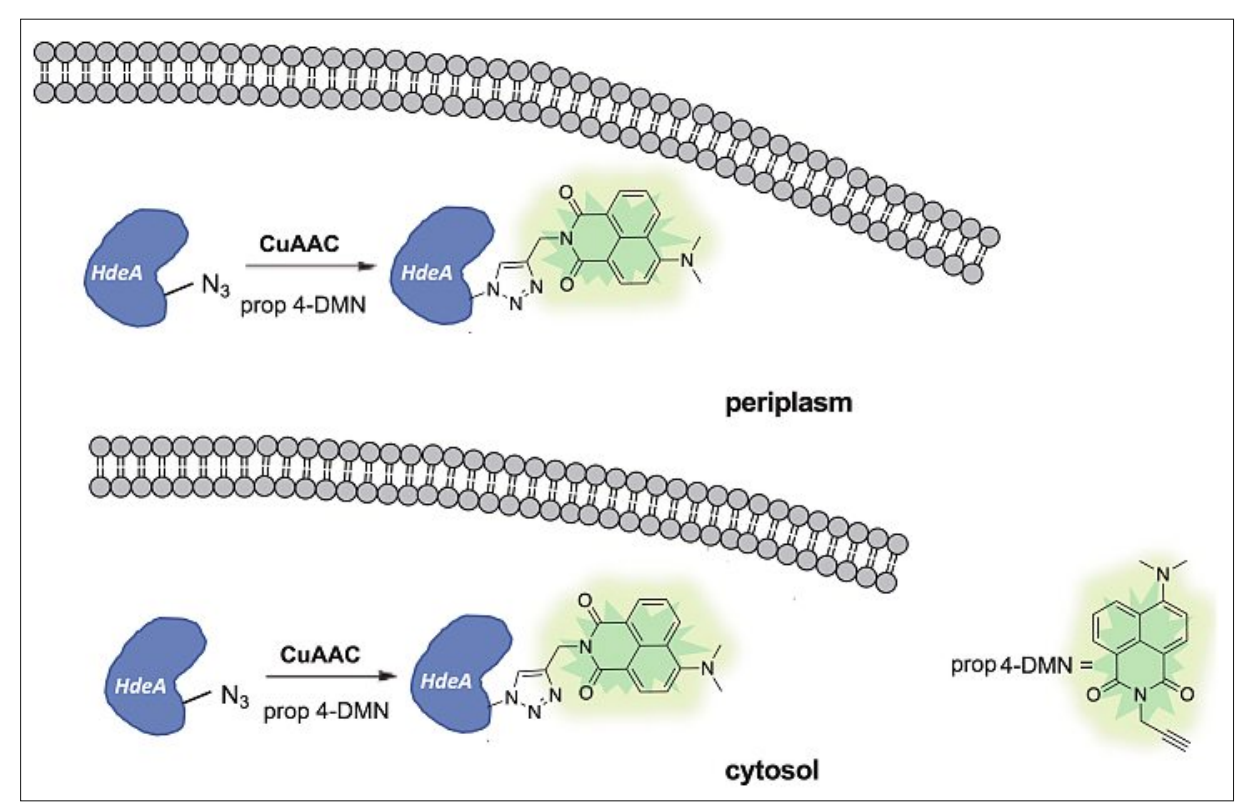

Fig. 1. Protein modifications with CUAAC reactions. Representation of a CuAAC modification of HdeA protein in E coli. ${ }^{[31]}$

A. Ting and coworkers reported an elegant and efficient version of the $\boldsymbol{C u} \boldsymbol{A} \boldsymbol{A C}$ relying on a favored interaction of the azide with the copper complex owing to the presence of a neighboring pyridine capable of chelating the $\mathrm{Cu}(\mathrm{I})$ ion. The strategy not only allows to accelerate the reaction, but also to reduce the toxicity of $\mathrm{Cu}(\mathrm{I})$. The efficiency of this approach was demonstrated with its application in the modification of proteins on the surface of human embryonic kidney (HEK) cells. ${ }^{[10]}$

More recently, C. Cai and co-workers demonstrated that linking copper tris(triazole) ligands to cell penetrating peptides enables protein modification inside cells by using the $\boldsymbol{C} \boldsymbol{u} \boldsymbol{A} \boldsymbol{A C}$. However, the efficiency of the reaction is hampered by the presence of millimolar concentration of glutathione in the cytosol of the cells. ${ }^{[32]}$ promote a $\boldsymbol{C u A A C}$ of 3-azido-7-hydroxycoumarin and $p$-ethynylanisole to generate the fluorescent triazole product $\mathbf{1}$ inside bacteria or living mammalian cells (Scheme 1b). The reaction required the use of a large amount of reducing ascorbate. The exact $\mathrm{Cu}(\mathrm{I})$ species promoting the reaction is not clear. With these heterogeneous copper catalysts they were also able to synthesize bioactive triazole products inside cells; products that otherwise might be difficult to deliver. ${ }^{[34]}$

The group of M. Bradley and coworkers explored the use of polymeric supported copper nanoparticles (CuNPs) as catalytic nanoreactors. These CuNPs were able to promote a $\boldsymbol{C u A A C}$ of small molecule azides and alkynes in the presence of living cells. The reaction was applied to the synthesis of a triazole cytotoxic anti- 
cancer agent derived from Combretastatin (2) (Scheme 1c). However the reaction was confirmed to take place in the extracellular medium, rather than inside cells. ${ }^{[35]}$

Later on, in 2018, the group of J. L. Mascareñas demonstrated that water-soluble copper(I) complexes featuring designed ligands can tune the cell uptake and reactivity of $\mathrm{Cu}(\mathrm{I})$ complexes and thereby promote intracellular $\boldsymbol{C} \boldsymbol{u} \boldsymbol{A} \boldsymbol{A C}$ annulations of small, abiotic and freely diffusible molecules. In particular, they demonstrated the intracellular reaction between anthracenyl azide $\mathbf{3}$ and propargyl alcohol in presence of a predefined $\mathrm{Cu}$ (I) complex [Cu(BTTE)] $\left(\mathrm{PF}_{6}\right)$, and in absence of ligands or ascorbate, to yield the fluorescent adduct 4 (Scheme 1d). ${ }^{[36]}$

These results suggest that playing with ligands, it might be possible to design $\mathrm{Cu}(\mathrm{I})$ complexes with low toxicity, good transport properties and an appropriate balance between reactivity and stability. It might even be possible to target different cells, or subcellular organelles, which could open new avenues on the applicability of the $\boldsymbol{C} \boldsymbol{u A A C}$ in living settings and on its potential translation to biomedicine. One important advantage of the $\boldsymbol{C} \boldsymbol{u} \boldsymbol{A} \boldsymbol{A C}$ reaction with respect to other metal-promoted processes is related to the good rates that can be achieved, which allows to use very low concentrations of the substrates. The main disadvantages are still associated to the oxidative lability and cytotoxicity of $\mathrm{Cu}(\mathrm{I})$ complexes, as well as the difficulties in controlling the bioorthogonality.

\subsubsection{Ruthenium}

Several catalytic annulations of alkynes mediated by ruthenium complexes have been reported.[37] In 2005 Fokin and Jia described a ruthenium version of the $\boldsymbol{C u} \boldsymbol{A} \boldsymbol{A C}$, with the important difference that the reaction can be achieved with disubstituted alkynes, while the $\boldsymbol{C} \boldsymbol{u} \boldsymbol{A} \boldsymbol{A} \boldsymbol{C}$ only works efficiently with terminal alkynes. ${ }^{[38]}$ However, the reaction was described only in organic solvents and provides a mixture of regioisomeric adducts. Recently, the group of J. L. Mascareñas developed a water-compatible Ru-promoted annulation involving azides and thioalkynes $(\boldsymbol{R u A t A C}){ }^{[39]}$ The reaction was better promoted by the complex [RuCp*(COD) $\mathrm{Cl}$ ( $\mathrm{A})$ at room temperature, and is highly bioorthogonal, as it can be achieved in water, in phosphate-buffered saline (PBS) solutions containing biomolecules (glutathione, amino acids, peptides), in complex biological media such as cell lysates and fetal bovine serum, and even in the presence of living bacteria (Scheme 2). ${ }^{[39]}$

While these results are very appealing, and ruthenium is less toxic than copper, the application of $\boldsymbol{R} \boldsymbol{u A t A C}$ in living settings

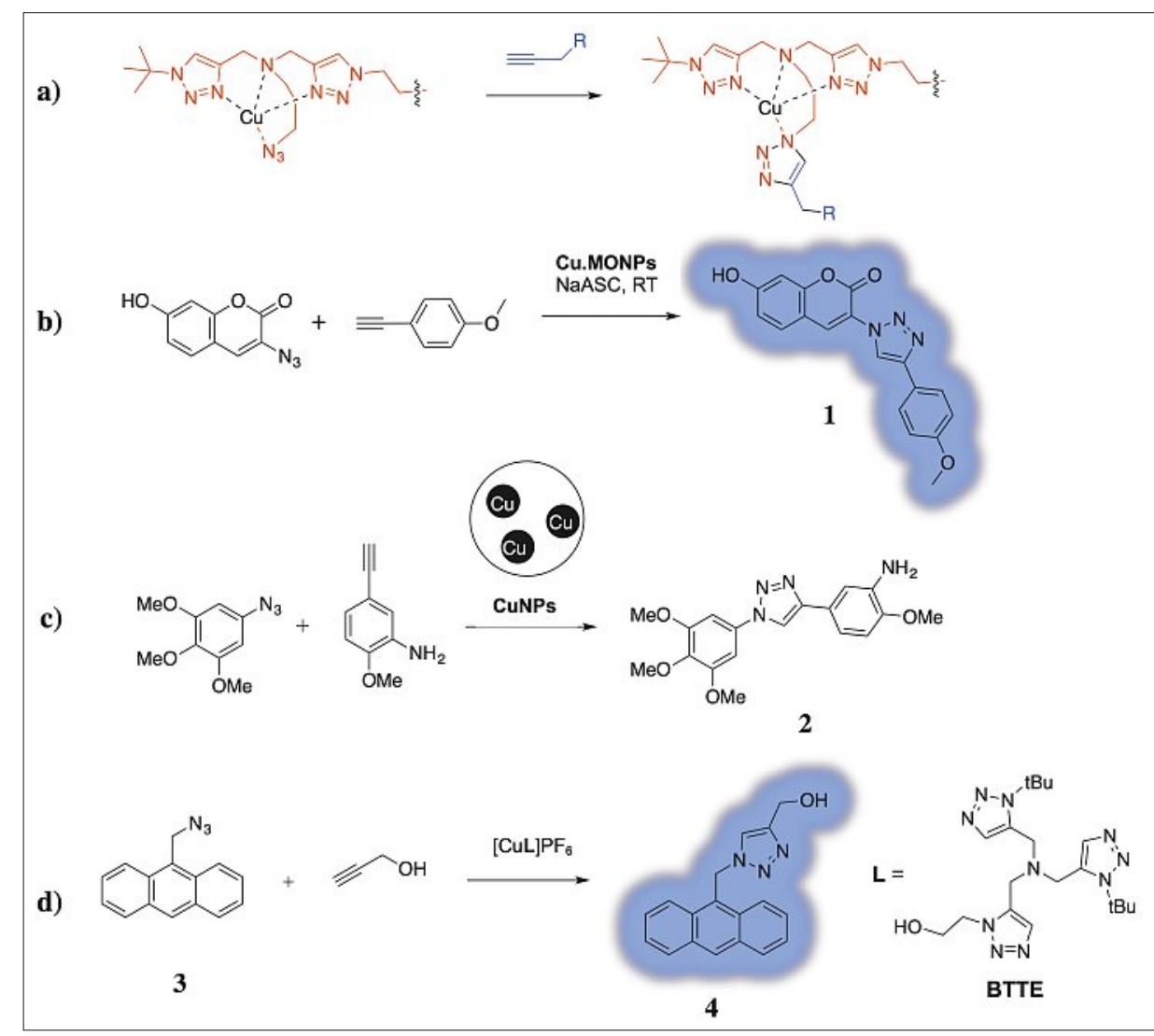

Scheme 1. CuAAC reactions of small molecules achieved in cellular settings. a) Chelating azides used by Taran et al.:;[3] b) Zimmerman et al. used polymeric copper nanoparticles (Cu-MONPs); ${ }^{[34]}$ c) Bradley et al. employing polystyrene supported CuNPs ${ }^{[35]}$ and d) Mascareñas et al. described discrete $\mathrm{Cu}(\mathrm{l})$ complexes for the CuAAC in living cells. ${ }^{[36]}$

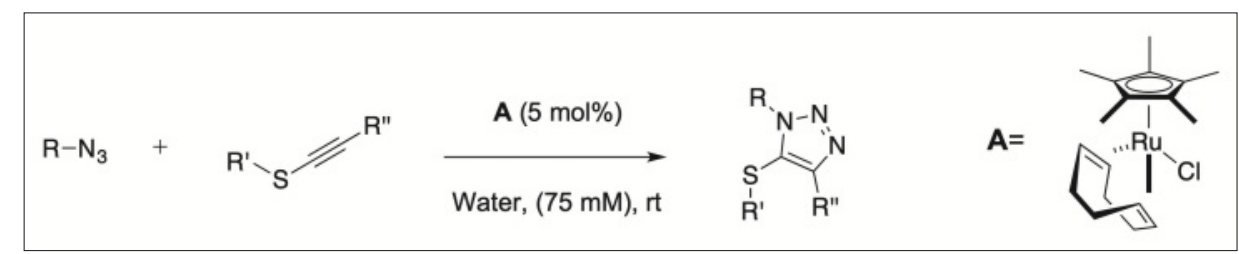

Scheme 2. Ruthenium-catalyzed azide-thioalkyne cycloadditions in aqueous media (RuAtAC). ${ }^{[39]}$

was not yet demonstrated, as it would require to increase the reaction rate so that it can be achieved with micromolar amounts of the reactants.

\subsubsection{Iridium and Rhodium}

Very recently, there have been several reports on the application of other late transition metals to promote azide-alkyne annulations, some of which tolerate oxygen and water. In 2014, Jia and coworkers reported the use of $\operatorname{Ir}(\operatorname{cod}) \mathrm{Cl}_{2}$ to promote the annulation of thioalkynes, albeit most of the examples were described in organic solvents. ${ }^{[40]}$ More recently, Huang and coworkers reported a rhodium-catalyzed azide-alkyne cycloaddition of internal ynamides, and demonstrated that the reaction is also operative in water. ${ }^{[41]}$

The use of $\mathrm{Rh}$ and Ir in living settings has not yet been explored, except for a redox reaction promoted by an iridium reagent that is taking place in cellular contexts (see Section 4.2).

\subsection{Couplings}

Transition-metal catalyzed cross-coupling reactions can be considered among the more relevant transformations in the field of synthetic and medicinal chemistry. Being able to achieve these bond-forming reactions in aqueous media and bio-relevant environments would also be of prime relevance. Despite the enormous difficulties associated with this challenge owing to the common requirement of organic solvents or additives to obtain good results, and the bimolecular nature of the processes, a number of examples have demonstrated the viability of achieving palladium-catalyzed SuzukiMiyaura, Sonogashira or Heck reactions in complex aqueous media.

\subsubsection{Palladium}

Suzuki-Miyaura couplings. Work on the topic has been pioneered by the group of B. G. Davis, who demonstrated that it is possible to achieve Suzuki-Miyaura crosscouplings on suitably modified proteins 
in biological compatible settings, using $\mathrm{Pd}(\mathrm{OAc})_{2}$ together with a 2-amino-4,6dihydroxypyrimidine ligand (L) (Scheme $3)^{.42]}$ Indeed, they were even able to promote such a carbon-carbon bond forming reaction on the cell-surface of $E$. coli, using genetically 'tagged' aryl halide-containing porin channels. ${ }^{[13]}$ Reportedly, the major drawbacks of the reaction are related to its incompatibility with thiols, such as that of glutathione. to the use of Sonogashira cross-coupling reactions in aqueous solvents. They even demonstrated the viability of using the reaction in E. coli to modify an overexpressed ubiquitin protein which incorporates an homopropargylglycine residue. ${ }^{[14]}$ They have also expanded the application of the cross-coupling reaction to the surface of mammalian cells, being able to modify alkynyl-equipped proteins bound to the cellular membrane. ${ }^{[46,47]}$

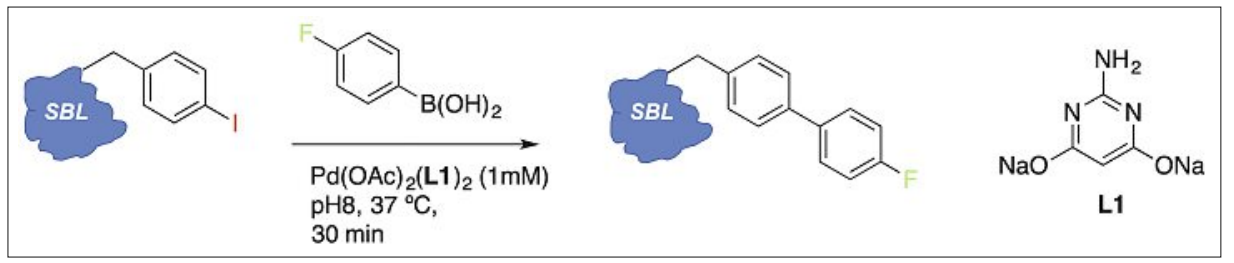

Scheme 3. Modification of the bacterial protein SBL by Suzuki-Miyaura cross coupling. ${ }^{18} \mathrm{~F}$ labelling of bacterial protein SBL through $\mathrm{C}-\mathrm{C}$ bond formation employing $\mathrm{Pd}(\mathrm{OAc})_{2}$ as palladium source and the ancillary ligand L1, published by Davis and coworker. ${ }^{[42]}$

\subsubsection{Gold}

Amidations. Tanaka et al. reported in 2017 an $\mathrm{Au}(\mathrm{III})$ complex capable of promoting an amidation reaction even in living mice. This $\mathrm{Au}(\mathrm{III})$ conjugate 6 possesses a 7-diethylaminocoumarin linked to a water-compatible cyclometalated Au(III) complex via a short PEG linker (Scheme 5). The authors indicate that this compound is able to bind to specific sugars in different tissues and claimed that the resulting hybrids are capable of promoting an amide bond formation between fluorescent propargyl ester probes and nearby surfaceprotein amines (e.g. lysine side chains). ${ }^{[48]}$

\subsection{Cyclizations}

Cyclization reactions allow cyclic products to be built from acyclic precursors, and usually involve the formation of at least one new bond. Despite their constructive power, metal-promoted, aqueous
While it is clear that achieving palladium-promoted Suzuki-Miyaura cross couplings inside living mammalian cells is far from easy, in 2011 the group of Bradley ${ }^{[16]}$ indicated that $\operatorname{Pd}(0)$ nanoparticles supported on polystyrene microspheres $\left(\mathrm{Pd}^{0}-\mathrm{MS}\right)$ can promote the coupling of the designed substrates inside HeLa cells (Scheme 4a), albeit the cells were fixed before analyzing the results. The phosphonium moiety in the product allows for its mitochondria localization. ${ }^{[16]}$ Later on, they also explored an in cellulo dual drug synthesis promoted by these small $\operatorname{Pd}(0)$ microspheres. Specifically, their $\operatorname{Pd}(0)$ nanoparticles promoted the synthesis of the anticancer agent $\mathbf{5}$ via Suzuki-Miyaura cross-coupling of two benign precursors (Scheme 4b), and the simultaneous depropargylation (see Section 3.2.1) of a fluorouracil derivative. ${ }^{[43,44]}$

A interesting recent article by $\mathrm{Qu}$ and coworkers described the use of light-activatable heterogeneous palladium species for promoting bioorthogonal coupling reactions in living cells. ${ }^{[45]}$ The authors modified macroporous silica- $\operatorname{Pd}(0)$ with supramolecular complexes of azobenzene (Azo) and $\beta$-cyclodextrin (CD), so that upon light irradiation it is possible to modulate such interactions and hence the access of substrates to catalytic sites. ${ }^{[45]}$

These advances in the implementation of Suzuki-Miyaura cross couplings have been essentially restricted to the use of $\operatorname{Pd}(0)$ nanostructured species as catalytic materials. The development of discrete palladium catalysts capable of achieving intracellular carbon-carbon bond forming reactions remains to be demonstrated.

Sonogashira couplings. Q. Lin and co-workers made important contributions

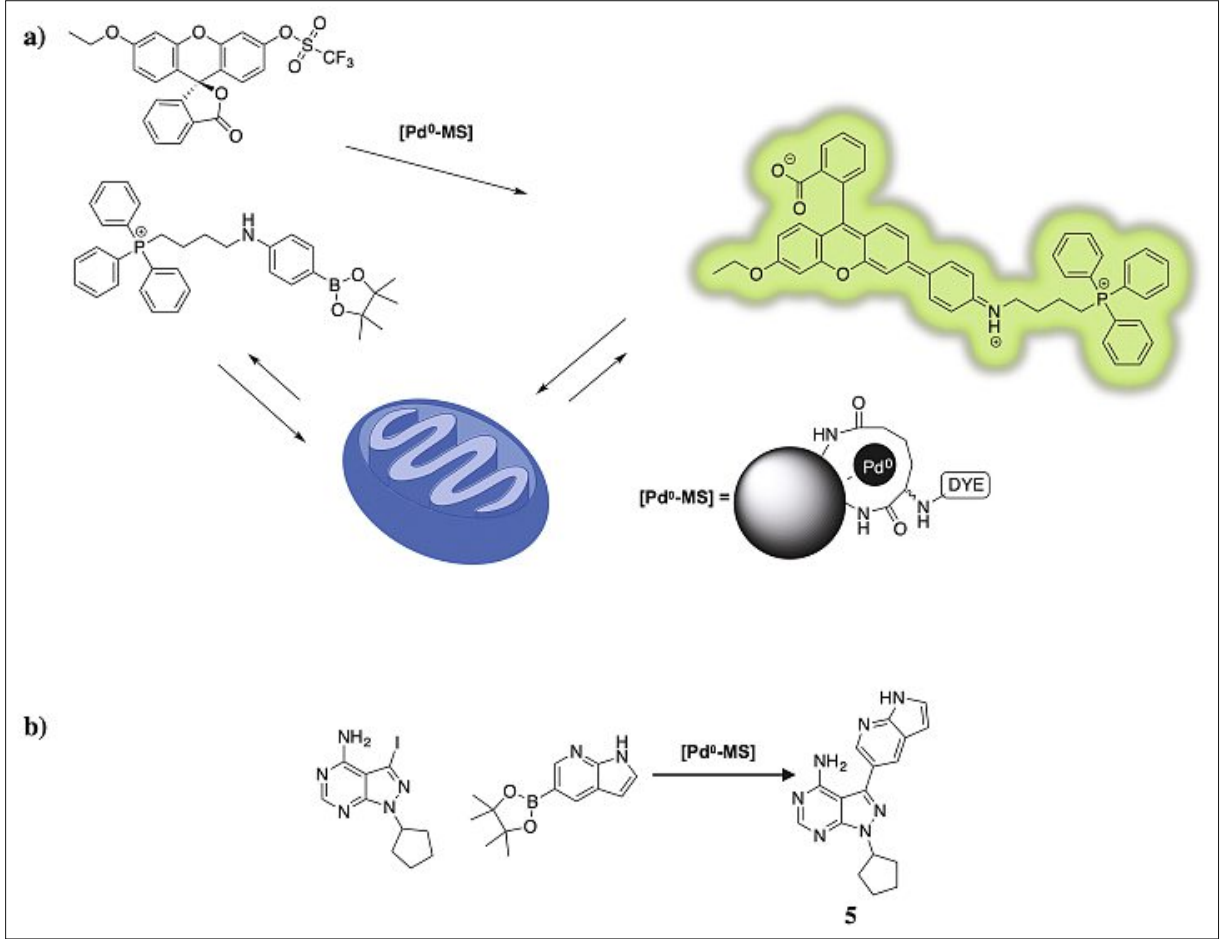

Scheme 4. Suzuki-Miyaura cross coupling reactions claimed to occur in HeLa cells. a) Fluorescent probe generated by Suzuki-Miyaura cross coupling promoted by $\mathrm{Pd}(0)$-microspheres. The presence of the triphenylphosphonium group allowed accumulation in the mitochondria ${ }^{[16]}$ and b) Synthesis of the anticancer agent PP-121 (5) using the Suzuki-Miyaura cross-coupling. ${ }^{[43]}$
Scheme 5. Aupromoted amidations. a) Au(III) cyclometallated complex 6 used in the studies; and b) proposed amide bond formation by alkynylester activation. ${ }^{[48]}$ 
compatible bioorthogonal cyclizations have been rarely pursued.

\subsubsection{Gold}

The development of aqueous compatible transformations promoted by gold complexes is still in a very early stage. Gold was considered an inert element for many years, however, in the last two decades there has been a boost in the development of goldcatalyzed reactions. [49-57] The reactivity of $\mathrm{Au}(\mathrm{I})$ and $\mathrm{Au}(\mathrm{III})$ complexes is associated to their carbophilicity, in particular, to the ability of these metals to coordinate and activate unsaturated bonds. While the compatibility of this reactivity with water and especially with the presence of biological media was dubious, in 2010, Kim and coworkers reported a gold reactive alkynyl probe that is able to detect the presence of $\mathrm{Au}(\mathrm{III})$ salts in cells, by taking advantage of the reactivity promoted by the metal. Specifically, the authors described a goldpromoted cyclization that provides fluorescent coumarin products. ${ }^{[58]}$ Later, in 2014 , Ahn and coworkers reported another strategy for sensing gold salts in cells based on gold(III)-promoted oxa-cyclizations, with concomitant ring opening of a rhodaminelactam ring. ${ }^{[59]}$

Just recently, the group of J. L. Mascareñas reported a series of $\mathrm{Au}(\mathrm{I})$ phosphine complexes capable of promoting the cyclization of a designed procoumarin 7 to give the corresponding coumarin product $\mathbf{8}$, even in cellular contexts (Scheme 6). The authors were also able to demonstrate the viability of combining the gold-promoted reaction with a deallylation process promoted by ruthenium (9 to 10), so that both reactions could be carried out inside living HeLa cells in a fully bioorthogonal and mutually orthogonal manner (Scheme 6). ${ }^{[60]}$

\subsubsection{Palladium (Heck)}

To the best of our knowledge, the only example of a palladium-mediated cyclization carried out in the presence of living cells has been recently reported by Weissleder and coworkers. ${ }^{[18]}$ The authors demonstrated the possibility of assembling a coumarin fluorophore (7-diethylaminocoumarin) from its non-fluorescent precursor in HT1080 cells, via intramolecular Heck coupling promoted by a palladium precatalyst $\left(\mathrm{PdCl}_{2}(\mathrm{TFP})\right.$, encapsulated in a polymeric formulation based on polylactic acid-co-glycolic acid (PLGA) and polyethylene glycol-poly lactic acid-coglycolic acid (PLGA-PEG, Scheme 7). ${ }^{[18]}$

\subsubsection{Ruthenium (Ring-closing Metathesis)}

The ring-closing metathesis reaction is a well-known, extremely effective manner of building cyclic alkene products from

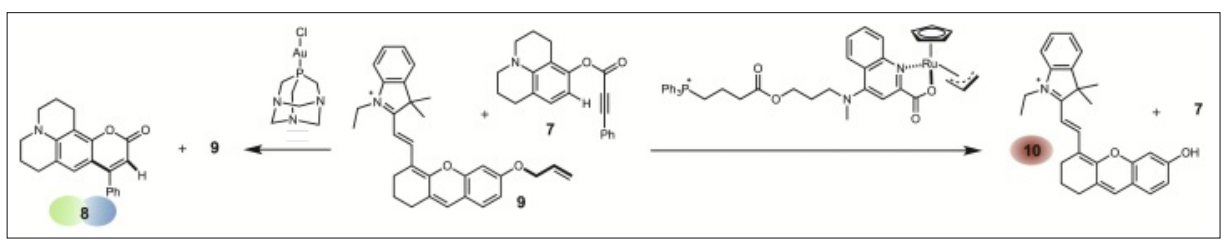

Scheme 6. Concurrent $A u(I)$ and $R u(I v)$ catalysis inside HeLa cells. Schematic representation of the ruthenium and the gold-intracellular transformations mediated reactions, each one of the obtained products possess different emissive properties that can therefore be readily monitored. ${ }^{[60]}$
Scheme 7. Pd catalyst encapsulation and Heck Pd cyclization. Representation of the encapsulation process of the palladium precatalyst, and Heck cyclization promoted by the encapsulated derivative. ${ }^{[18]}$
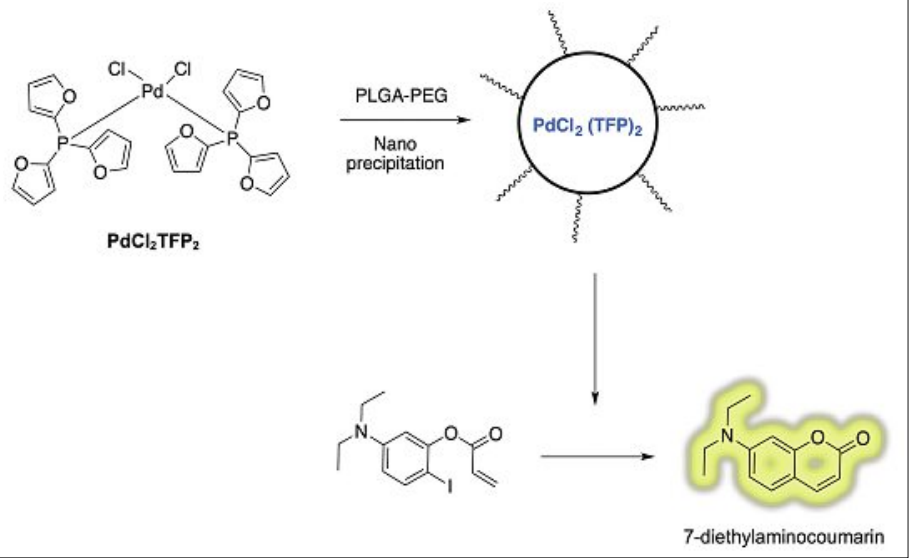

dialkenyl acyclic precursors. T. Ward and coworkers have recently demonstrated the viability of achieving such reactions in the periplasm of E. coli using artificial metalloenzymes equipped with the required ruthenium catalysts. These metalloenzymes were built using their previously developed biotin-streptavidine (biot-Sav) strategy, based on equipping the biotin moiety with different types of metal complexes, so that upon assembling with streptavidine they generate such metalloproteins. [61] To promote the ring-closing metathesis, they built ruthenium-based metalloenzymes from the corresponding biotin conjugates (biot-Ru, Fig. 2).[62]

The above examples demonstrate the viability of achieving bond-forming reactions in complex aqueous media, and in some cases even in living settings.
Therefore, the design of adequate ligands for $\mathrm{Cu}(\mathrm{I})$ ions has allowed $\boldsymbol{C u A A C}$ annulations of small abiotic substrates to be performed inside living cells. The toxicity of copper has promoted the development of related annulations promoted by other metals. While recent publications demonstrate the viability of using ruthenium, rhodium or iridium catalysis for azide-alkyne annulations in aqueous media, applications in living cells remain to be demonstrated.

Palladium-promoted cross-coupling reactions have been successfully achieved in cells, but they seem to require nanostructured materials, or protected forms of the palladium. However, some isolated examples indicate that discrete Pd complexes can promote the covalent modification of proteins in biological compatible media and, in some cases, in the surface of bacte-

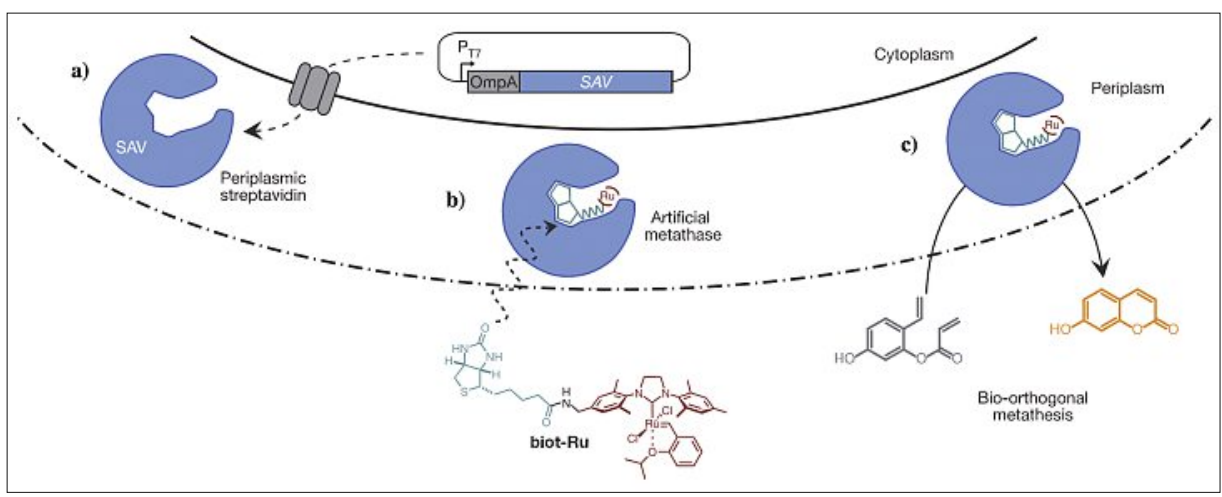

Fig. 2. Biot-Ru-Sav metalloenzyme at the bacterial periplasm. a) Streptavidin is secreted to the periplasm by fusion to an $\mathrm{N}$-terminal signal peptide from the outer membrane protein $\mathrm{A}(\mathrm{OmpA})$; b) the biotinylated organoruthenium catalyst binds to the Sav forming the biot-Ru-Sav; c) Catalytic bio-orthogonal metathesis reaction promoted by the biot-Ru-Sav metalloenzyme at the periplasm of $E$. Coli. Adapted with permission from ref. [62], copyright 2017 Nature Publishing Group. 


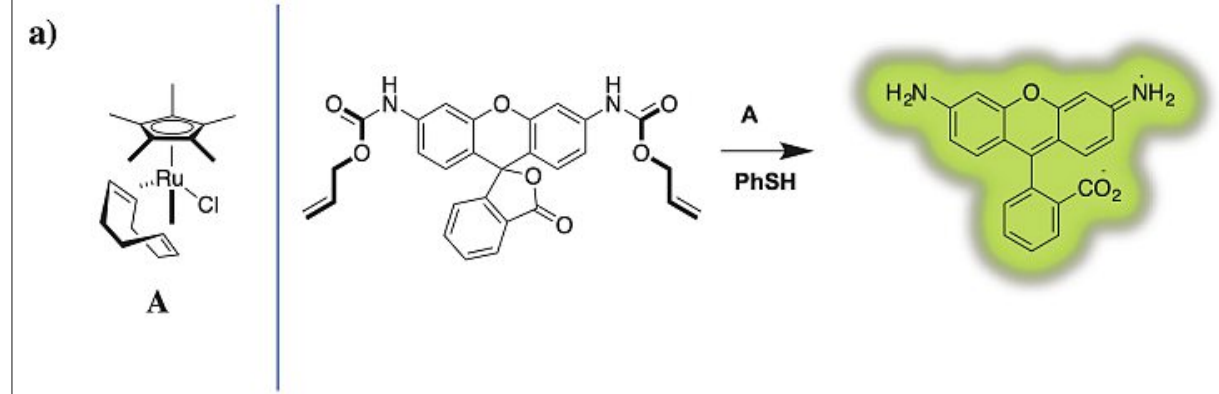

b)
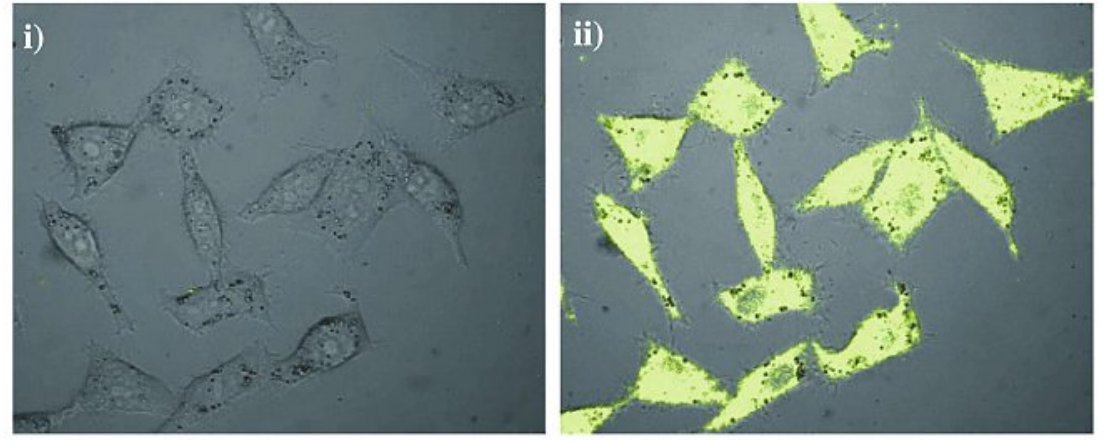

Fig. 3. Ruthenium-promoted deprotection. a) Representation of the uncaging of Rhodaminealloc promoted by $\mathbf{A}$ and $\mathbf{b}$ ) imaging of HeLa cells: i) before the addition of the Ru catalyst to cells preincubated with Rhodamine-alloc, and $\mathrm{PhSH}$ and ii) 15 minutes after the addition of ruthenium complex A. Adapted by permission from ref. [19]. Copyright 2006, Wiley-VCH.

ria. Preliminary results indicate the viability of achieving other types of bond-forming reactions, especially cyclization processes, using gold or ruthenium catalysts.

While much remains to be learned and achieved, these results provide a solid proof of concept, and therefore, in the coming years, we should expect both the discovery of new reactions, and the development of important biological applications either related with the controlled generation of drugs or with the building of primitive, non-natural metabolisms.

\section{Bond-cleaving Reactions}

\subsection{Removal of Allyl/Alloc Groups}

\subsubsection{Ruthenium}

In 2006, the group of E. Meggers published a pioneering work on the use of metal catalysis in living cells. Specifically, they reported the removal of allylcarbamate-protecting groups in HeLa cells promoted by ruthenium (II) complexes.[19] They could monitor the reaction in the cellular settings, because the substrate, a bisallylcarbamate derivative of Rhodamine 110 is essentially non fluorescent, but provides green-emitting Rhodamine when deprotected by the action $[\mathrm{RuCp} *(\mathrm{COD}) \mathrm{Cl}]$ (A) and thiophenol (Fig. 3).

The group of J. L. Mascareñas reported an application of this rutheniumbased strategy for the controlled activation of DNA binders like 4',6-diamidine-2'phenylindole (DAPI), ethidium bromide (EtBr) and bisbenzamidines ${ }^{[63]}$ inside living mammalian cells. These compounds, a)

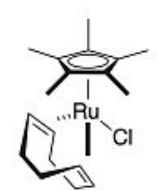

A

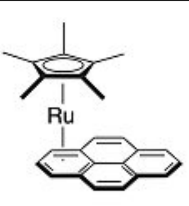

B ing the complex $\left[\mathrm{RuCp} *\left(\eta^{6}-\right.\right.$ pyrene $\left.)\right] \mathrm{PF}_{6}$ (Fig. 4, B), which can be activated (detachment of the pyrene ligand) by irradiation with UV light $(\lambda=330 \mathrm{~nm})$. $^{[65]}$

As already commented, these uncaging strategies employing $\mathrm{RuCp}^{*}(\mathrm{COD}) \mathrm{Cl}$ (A) required the use of $\mathrm{PhSH}$ as additive to favor the deallylation process; a compound that is toxic to cells. In 2014 Volker and Meggers demonstrated that using Kitamura's type of ruthenium catalysts, which are equipped with quinoline ligands, ${ }^{[66,67]}$ the addition of this external nucleophilic thiol is not needed; the glutathione present in the cells is strong enough to ensure the turnover in the catalytic process. Indeed, they demonstrated that with this type of ruthenium complex the in vitro turnover number (TON) of the reaction is considerably higher than that obtained with the original complex A. This activity can be even further tuned by changing the substitution in the position 4 of the quinoline ligand (Fig. 4, complexes C-E). ${ }^{[68]}$

In 2016, J. L. Mascareñas and coworkers demonstrated that it is possible to engineer the ligands of Kitamura's ruthenium complexes to introduce different cellular targeting groups (Fig. 4, complexes $\mathbf{F}-\mathbf{H}$ ). In particular, they found that using a triphenylphosphonium derivative the ruthenium complex accumulates in the mitochondria of living cells, where it is still able to promote the uncaging of the alloc-protected rhodamine. ${ }^{[69]}$ Importantly, the ruthenium complex $\mathbf{G}$ was not only tested towards standard fluorogenic probes, but also with b)

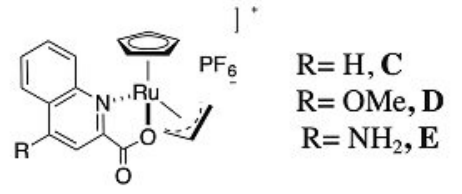

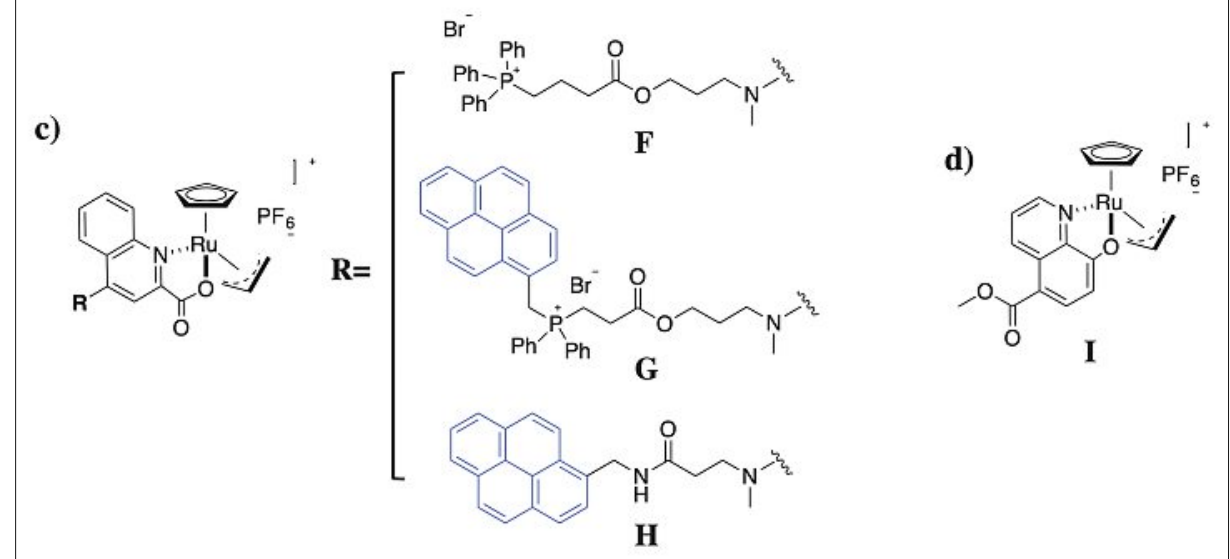

Fig. 4. Structure of several ruthenium complexes used as catalysts in biological settings. a) $\mathbf{A}^{[18]}$ and $\mathbf{B} ;{ }^{[65]}$ b) Kitamura's derived Ru(iv) catalysts $\mathbf{C}-\mathbf{E}$ employed by Meggers et al. ${ }^{[68]} \mathrm{c}$ ) catalysts $\mathbf{F}-\mathbf{H}$ synthetized by Mascareñas et al., in the study of mitochondrial specific catalysis ${ }^{[69]}$ and d) second generation of quinoline derived Ru(IV) catalyst (I) reported by Meggers et al. ${ }^{[70]}$ 
the caged protonophore 1-(allyloxy)-2,4dinitrobenzene. The in situ uncaging generates 2,4-dinitrophenol that works as a very efficient uncoupler of the mitochondrial membrane potential. ${ }^{[69]}$

In 2017, T. Volker and E. Meggers described a new generation of quinoline derived $\mathrm{Ru}$ (IV) complexes (Fig. 4, I) that present improved stability and excellent catalytic potential under bio-relevant conditions, even in blood serum. ${ }^{[70]}$

All these data confirm that appropriately designed $\mathrm{Ru}$ complexes are able to achieve very interesting deallylation reactions in biologically relevant aqueous mixtures and even in living cells, in a bioorthogonal manner and without generating major cytotoxicity.

\subsubsection{Palladium}

Bradley and Unciti-Broceta have pioneered the use of palladium nanostructured materials to promote chemical transformations in living settings, as was already commented above (see Section 2.2.1). These $\operatorname{Pd}(0)$-microspheres were demonstrated to be highly effective for the uncaging of rhodamine-alloc probes even in cellular systems. ${ }^{[16]}$

In 2017 R. Weissleder and co-workers reported another example of the applicability of palladium catalysts for deallylation reactions in living settings. ${ }^{[18]}$ A polymerembedded palladium complex is very effective in the deprotection reaction of rhodamine-alloc probes as well as in the uncaging of a Doxorubicin-alloc prodrug. These experiments were even carried out in vivo using mice, with very promising results. ${ }^{[18]}$

More recently, the group of Mascareñas demonstrated that discrete Pd(II) complexes with designed phosphine ligands present the right balance of reactivity and stability to achieve deallylation reactions in living Hela and Vero cells. Adequate modification of the phosphine ligands permitted a preferential accumulation of the complexes in the mitochondria, which as in the case of the ruthenium, allows for site specific transformations (Fig. 5). ${ }^{[71]}$

\subsection{Removal of Propargyl Groups \\ 3.2.1 Palladium}

Several groups have shown that palladium can also be used to uncage propargyl-protected functional groups. In 2014, the group of P. R. Chen reported the use of discrete $\mathrm{Pd}(\mathrm{II})$ catalysts to achieve chemical protein activations in living cells, using a depropargylation reaction of protected lysines (Scheme 8a). This uncaging strategy was used for the chemical rescue of a non-overexpressed bacterial enzyme phosphothreonine lyase $(\mathrm{OspF})$ within HeLa cells, using $\mathrm{Pd}_{2}(\text { allyl })_{2} \mathrm{Cl}_{2}$ as precatalyst. ${ }^{[17]}$ While removal of allyl groups

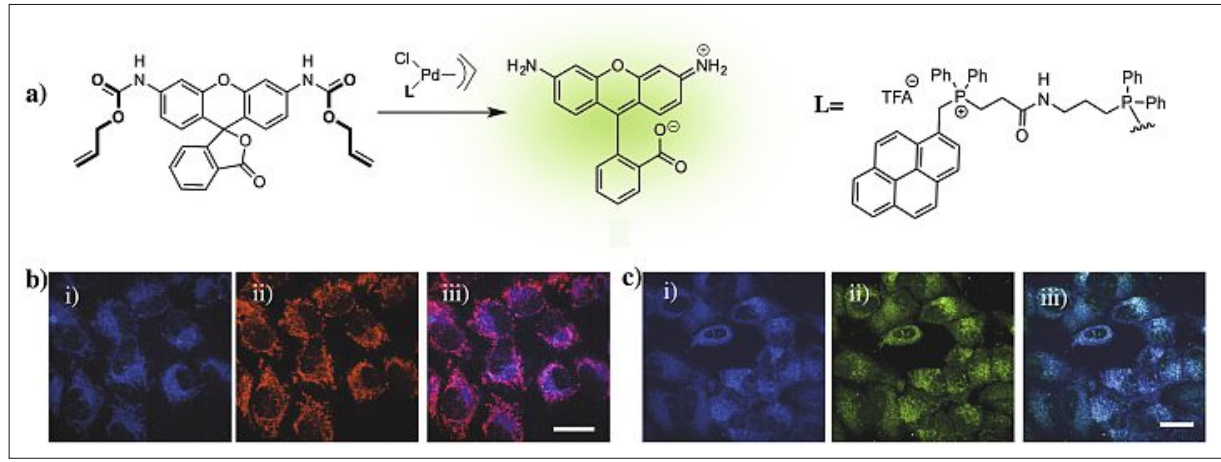

Fig. 5. Discrete Pd(II) complexes in living cells. a) Representation of the uncaging reaction; b) Colocalization of the Pd catalyst with TMRE in HeLa cells, observed $2 \mathrm{~h}$ after incubation with the palladium complex: i) Blue light emission of catalyst; ii) red light emission from the mitochondrial dye TMRE, iii) merged image of i) and ii). c) Pd-promoted reaction: i) blue light emission of the Pd catalyst; ii) green light emission from released Rhodamine 110, iii) merged image of i) and ii). Adapted with permission from ref. [71]. Copyright 2018 American Chemical Society.

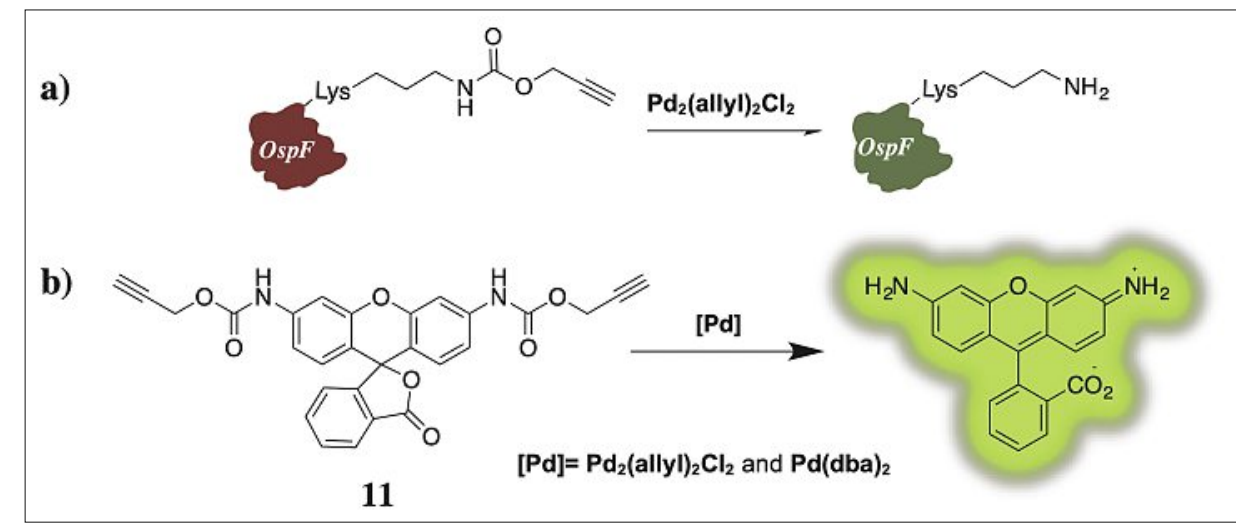

Scheme 8. Propargyl uncaging in living cells. Representation of the a) activation of the nonoverexpressed bacterial enzyme phosphothreonine lyase (OspF), and b) uncaging of a) the proccaged probe $11^{[17]}$

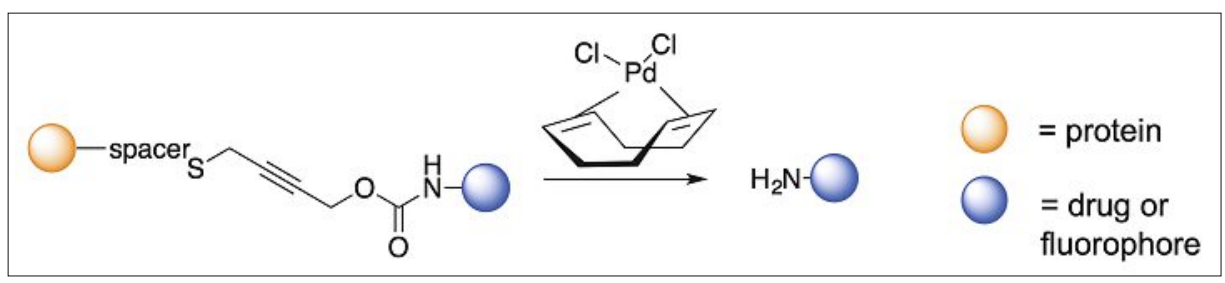

Scheme 9. A thioether-directed palladium-cleavable linker. Representation of the decaging of bifunctional propargyl carbamates in cultures of cancer cells. ${ }^{[73]}$

by palladium complexes likely involves $\operatorname{Pd}(0)$ reagents, the depropargylation mechanism might proceed via $\mathrm{Pd}(\mathrm{II} / \mathrm{IV})$ or $\mathrm{Pd}(0 / \mathrm{II})$ cycles.[17] The Pd-promoted uncaging reaction can be readily monitored using a di-propargylcarbamate-rhodamine probe (11, Scheme $8 \mathrm{~b}$ ), thanks to the green light emission of the released rhodamine product.

In a more recent publication about bioorthogonal reactions promoted by palladium catalysts, M. Bradley et al., presented homogeneous tagged carbenebased $\mathrm{Pd}(\mathrm{II})$ catalysts conjugated to a cell-penetrating peptide which are able to promote the deprotection of the rhodamine probe 11 inside PC-3 cells. ${ }^{\text {[72] }}$

G. Bernardes and coworkers have recently reported a palladium-promoted un- caging reaction involving internal propargylic thioethers (Scheme 9). In this report the uncaging is promoted by $\mathrm{Pd}(\mathrm{COD}) \mathrm{Cl}_{2}$ and the cleavage was performed in cell culture media. They even demonstrated that the strategy can be used for a controlled release of doxorubicine in the extracellular media; a compound which after internalization induces the death of the cell.[73]

Mascareñas and coworkers have also shown that the Pd-phosphine complexes used in the case of the deallylation reactions, can also be effective in the uncaging of propargyl protecting groups in probes 11 and 12 (Fig. 6). Furthermore, preliminary data suggested that there is some turnover in the reactions that take place inside living HeLa cells. ${ }^{[71]}$ 


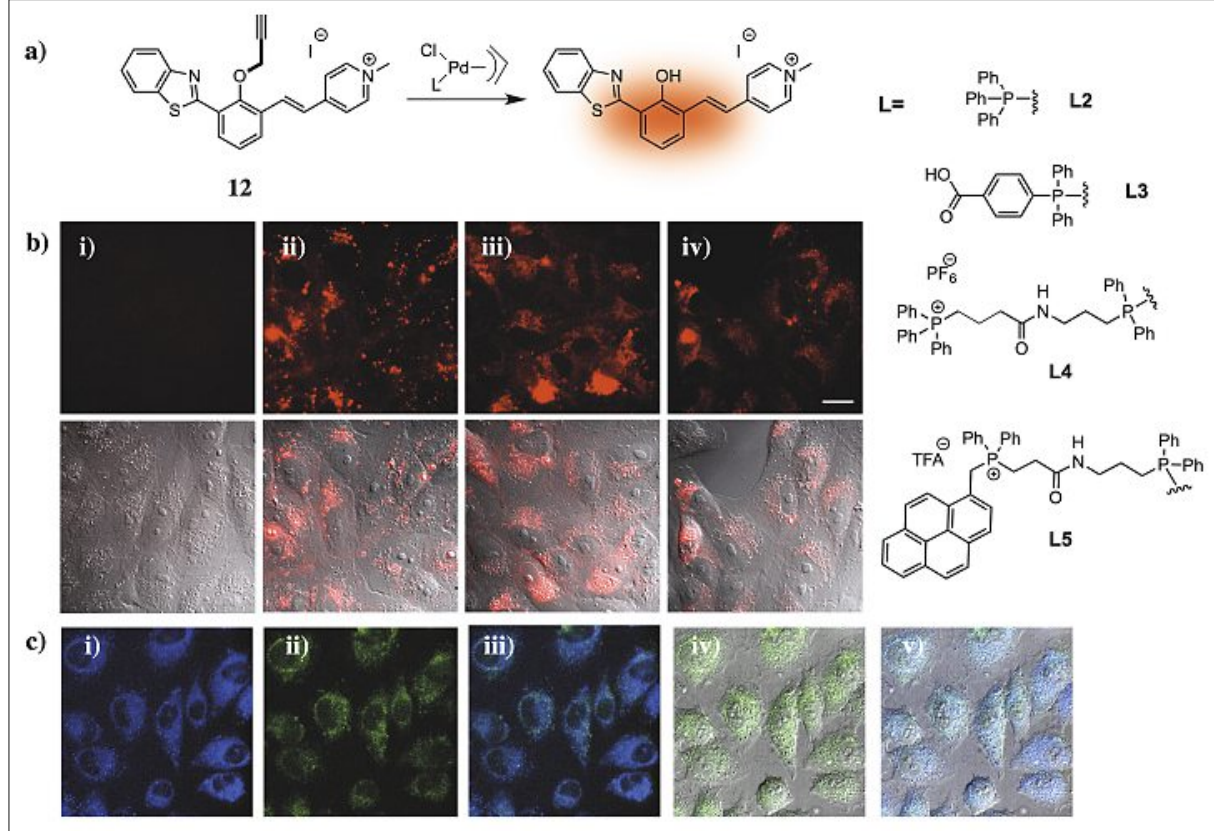

Fig. 6. Pd(॥) phosphine-derived complexes for in cellulo propargyl uncaging. a) Schematic representation of the uncaging reaction of the propargylated probe 12 and b) imaging of the reaction in Vero cells. First row - red channel; second row - brightfield and red channels merged (i: mock, ii: $L=L 2 ;$ iii: $L=L 3$ and iv: $L=L 4)$; c) Imaging of the uncaging of 11 in Hela cells. i) blue emission arising from the pyrene groups of Pd ligand L5 (blue channel), ii) green emission arising from the released Rhodamine 110 (green channel); iii) merged image of i) and ii); iv) merged imaging of the brightfield and the green channel and v) merged of the brightfield with the green and the blue channels. Adapted with permission from ref. [71]. Copyright 2018 American Chemical Society.

The group of P. R. Chen explored the modification of cell membranes by inducing cellular aggregation processes controlled by a palladium-promoted decaging of a propargyl protected form of neuramic acid (Neu5Proc). The best reaction results were obtained using $\operatorname{Pd}(0)$-nanoparticles instead of discrete commercially available $\mathrm{Pd}$ sources used in previous reports by the same group. ${ }^{[15]}$

In line with their previous work, Bradley and coworkers investigated the use of microspheres containing $\operatorname{Pd}(0)$ nanoparticles for the uncaging of a propargyloxy-protected probe in zebrafish. Inserting the palladium-microspheres in their yolk-sac, the authors were able to observe an increase in the fluorescence after incubation with the caged fluorogenic probe $\mathbf{1 1}$ due to the release of the fluorescent product. ${ }^{[74]}$ These $\mathrm{Pd}(0)$ nanoparticles $(9.2 \pm 1.5 \mathrm{~nm})$ can also be supported on a modular polymer (9.9 $\times 7.5 \mathrm{~mm})$ and the constructs are capable of inducing a depropargylation in cell culture media. ${ }^{[44]}$ The introduction of further modifications onto the $\operatorname{Pd}(0)$ microspheres with the cyclic peptide cRGDfE allowed an specific uptake by brain cancer cells, the uncaging of 5FU-proc and the generation of 5FU (Scheme 10). [43]

\subsubsection{Gold}

The application of gold complexes to promote the uncaging of propargylic probes is very recent, and to the best of 5FU-proc to release face, and the nucleophilic cooperative action of gold-tethered glutathione (GSH, Fig. 7).[75]

\subsection{Uncaging of Allene-protected Precursors}

Using commercially available $\mathrm{Pd}$ sources such as $\mathrm{Pd}_{2}(\text { allyl })_{2} \mathrm{Cl}_{2}, \mathrm{Pd}(\mathrm{OAc})$ and $\mathrm{Pd}(\mathrm{dba})_{2}$ among others, Chen and coworkers have also described the release of tyrosine-dependent proteins in living cells using genetically encoded proteins containing allene-protected tyrosines. ${ }^{[76]}$

In summary, an already important number of examples demonstrate the viability of achieving metal-promoted uncaging reactions involving bondcleavage processes in biological media and living settings. The reactions have been used for the release of fluorogenic probes and the activation of prodrugs or different type of biomolecules, including proteins. Some of the reactions have been even targeted to specific cells or to selective cell organelles, such as mitochondria.

\section{Redox Reactions}

\subsection{Ruthenium}

The group of Sadler has extensively demonstrated the viability of using organometallic $\mathrm{Ru}$ complexes as catalytic drugs to tune the redox potential of cells, as they interfere with the redox balance controlled by GSH and NAD/NADH. ${ }^{[77-79]}$ Almost all of these ruthenium (and some osmium) complexes work on endogenous rather than exogenous substrates, and therefore are not specifically discussed in this review. In a recent publication they have shown that novel organo-osmium catalysts improved
Scheme 10. Pdcatalyzed release of $5 \mathrm{FU}$. The Pdmediated uncaging of the cytotoxic $5 \mathrm{FU}$ takes place inside living glioblastoma cells. ${ }^{[43]}$
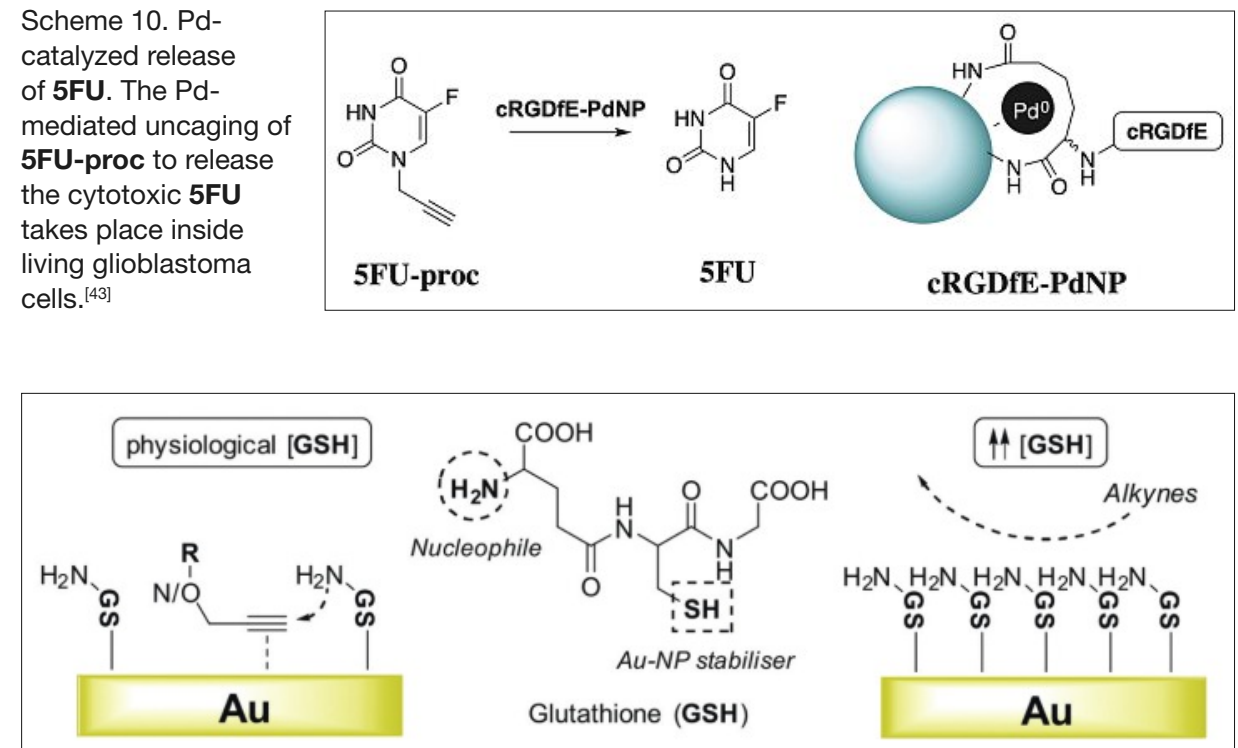

Fig. 7. GSH role on the Au-promoted alkynyl-ester activation. Reproduced by permission from ref. [75]. Copyright 2017. Wiley-VCH. 
ruthenium analogues under similar conditions in active transfer-hydrogenation processes, reporting the first example asymmetric transfer hydrogenation of pyruvate, with a high enantioselectivity in both aqueous and cellular media. ${ }^{[80]}$

The group of Winssinger has reported in cellulo protein labeling with a $\mathrm{Ru}(\mathrm{II})$ polypyridyl-conjugate for luminescence imaging and bioorthogonal photocatalysis. Specifically they achieved the photoreduction of $p$-azidobenzyl in biological settings. ${ }^{[81]}$ The same group also published a nucleic-acid templated chemical reaction in a live vertebrate using this type of photoreactive $\mathrm{Ru}(\mathrm{II})$ polypyridyl complexes. ${ }^{[82]}$

\subsection{Iridium}

The biological uses of iridium organometallic complexes have been mainly centered on their photophysical properties, as imaging agents, rather than in catalysis. The group of Sadler et al. also pioneered interesting studies on the viability of using organoiridium complexes as catalytic drugs inside cells to modulate the cellular redox balance. ${ }^{[78,79,83-85]}$

In 2017 L. H. Do and coworkers described iridium complexes capable of triggering the reduction of exogenous aldehydes through hydride transfer processes mediated by $\mathrm{NADH}$, in the presence of living cells. ${ }^{[86]}$ This bioorthogonal reduction was also studied with substrates such as BODIPY-CHO, which upon reduction to its alcoholic form BODIPY-OH experiences a change in the intensity of the fluorescence emission that can be detected by fluorescence microscopy (Fig. 8). ${ }^{[87]}$ Among the iridium catalysts used in this study (J-L, Fig. 8) the one bearing a pentametylcyclopendienyl ligand and a chelating ligand like $N$-phenyl-2pyridinecarboxamidate $(\mathbf{J})$ provided the best results. ${ }^{[87]}$

\subsection{Iron}

The application of iron complexes to promote non-natural intracellular transformations with exogenous substrates has been very limited to date. Indeed, to the best of our knowledge, there is only one report in this topic, consisting on the use of the iron(III) complex [Fe(TPP)]Cl (N) to promote the reduction of the Rhodamine-bisazide to Rhodamine 110 (Scheme 11). ${ }^{[88]}$

\section{Conclusions and Closing Remarks}

Achieving organometallic catalytic reactions of exogenous substrates in biological settings is an enormous challenge owing to the hostile aqueous, crowded

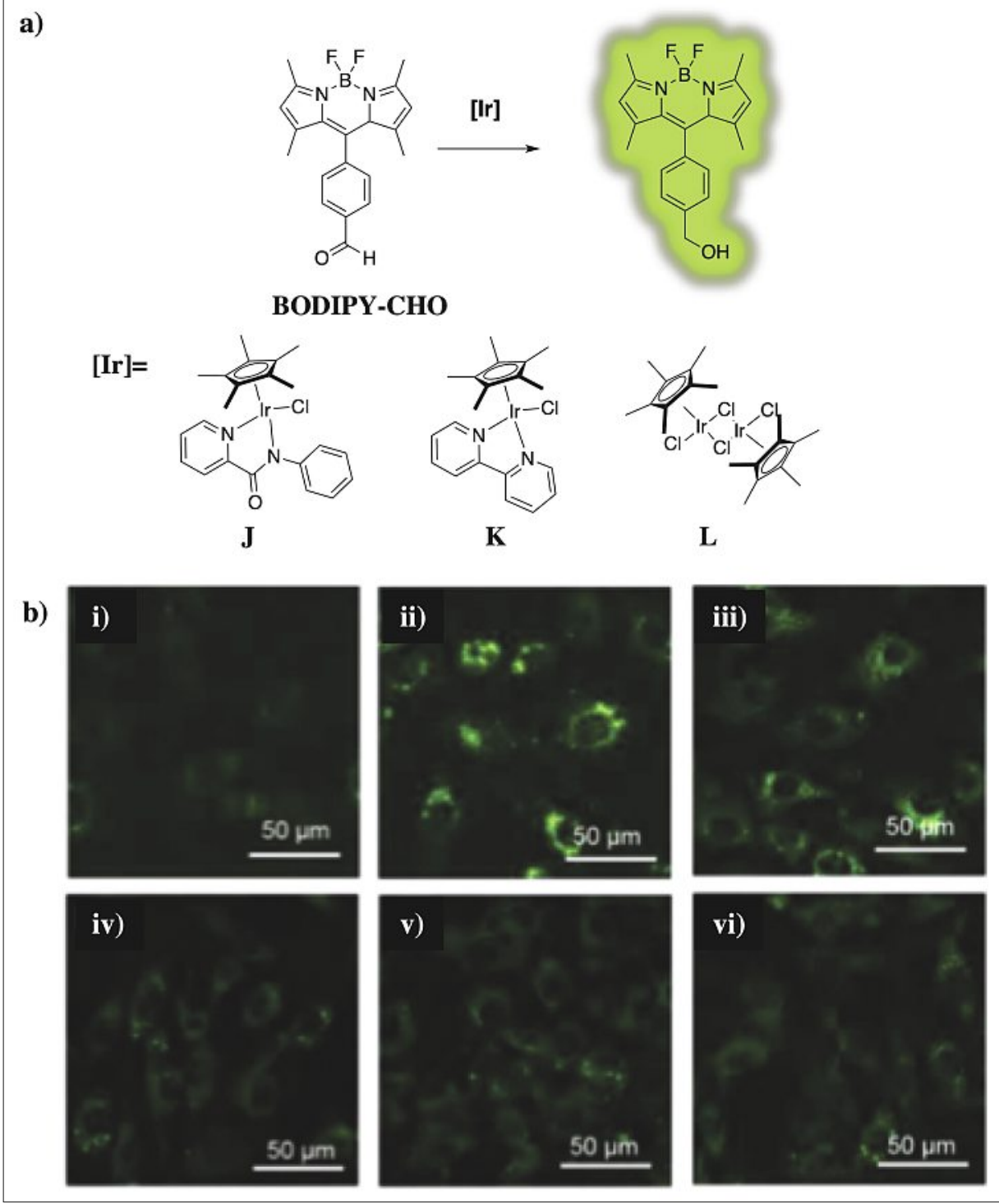

Fig. 8. BODPY activation mediated by Ir(II) promoted reduction. a) Representation of the BODIPYCHO reduction to BODIPY-OH promoted by Ir(III) catalysts $\mathbf{J}-\mathbf{L}$; b) imaging of $\mathrm{NIH}-3 \mathrm{~T} 3$ cells treated with i) BODIPY-CHO (30 $\mu \mathrm{M})$, ii) BODIPY-OH (30 $\mu \mathrm{M})$, iii) BODIPY-CHO (30 $\mu \mathrm{M}) / \mathbf{J}(20 \mu \mathrm{M})$, iv) BODIPY-CHO $(30 \mu \mathrm{M}) / \mathrm{L}(10 \mu \mathrm{M}), \mathrm{v})$ BODIPY-CHO $(30 \mu \mathrm{M}) / \mathrm{IrCl}_{3}(20 \mu \mathrm{M})$, and vi) BODIPY-CHO (30 $\mu \mathrm{M}) / \mathbf{J}(20 \mu \mathrm{M}) /$ sodium pyruvate $(10 \mathrm{mM})$. Sodium pyruvate was used to slow down the production of NADH which inhibited the hydride transfer from NADH to BODIPY-OH. Adapted by permission from ref. [87]. Copyright 2017, Wiley-VCH.

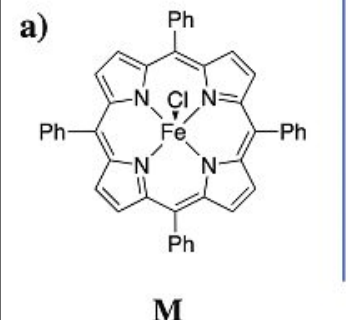

b)

Scheme 11. Azide reduction promoted by Fe-porphyrin-derived complex. a) Fe-porphyrin-derived complex M used for the reduction reaction; and b) iron-catalyzed reduction of the bis-azide-Rhodamine to generate the fluorescent Rhodamine 110. ${ }^{[88]}$

and compartmentalized environment of cells, the difficulties in finding a right balance between stability and reactivity of the metal complexes, and unavoidable toxicity problems. However, there are already an important number of results that demonstrate the feasibility of using different types of metals for such an endeavor. While the field is in its infancy, there is an constant growth in publications reporting new types of transformations in biological media and living 
cells. ${ }^{[20-25]}$ Further advances in the field requires a better knowledge of the molecular details of the intracellular reactions, the quantification of the processes, and the discovery of new biocompatible and efficient transformations. The implementation of some of these artificial metal catalysts in the form of catalytically active metalloproteins capable of working in vivo as artificial enzymes is especially challenging.

Further developments in the area will undoubtedly lead to important applications in cell biology, for the controlled activation or deactivation of specific biomolecules or the generation of a biocompatible artificial metabolism and in biomedicine for the targeted, amplified generation of drugs or biomolecular sensors.

\section{Competing Financial Interests}

The authors declare no competing financial interests.

\section{Acknowledgements}

We are thankful for the Financial support from the Xunta de Galicia (Centro singular de investigación de Galicia accreditation 20162019) and the European Union (European Regional Development Fund - ERDF), is gratefully acknowledged. We also thank support given by the Spanish grant SAF2013-41943-R, the Xunta de Galicia (GRC2013-041 and 2015CP082), the ERDF, and the European Research Council (Advanced Grant No. 340055). MMC thanks the Ministerio de Economía y Competitividad for the Postdoctoral fellowship (IJCI-2014-19326).

Received: July 14, 2018

[1] T. W. Hambley, Dalton Trans. 2007, 4929, DOI: 10.1039/b706075k

[2] M. Bottrill, L. Kwok, N. J. Long, Chem. Soc Rev. 2006, 35, 557, DOI: 10.1039/b516376p.

[3] M. Patra, G. Gasser, ChemBioChem 2012, 13, 1232, DOI: $10.1002 /$ cbic. 201200159.

[4] S. J. Lippard, Nat. Chem. Biol. 2006, 2, 504, DOI: 10.1038/nchembio1006-504.

[5] V. V. Rostovtsev, L. G. Green, V. V. Fokin, K. B. Sharpless, Angew. Chemie Int Ed. 2002, 41, 2596, DOI: $1.1002 / 1521$ $3773(20020715) 41: 14<2596:$ A ID ANIE2596>3.0.CO;2-4.

[6] C. W. Tornøe, C. Christensen, M. Meldal, $J$. Org. Chem. 2002, 67, 3057, DOI: 10.1021/ jo011148j.

[7] C. Wu, Y. Jin, T. Schneider, D. R. Burnham, P. B. Smith, D. T. Chiu, Angew. Chem. Int. Ed. 2010, 49, 9436, DOI: 10.1002/anie.201004260.

[8] A. Dumont, A. Malleron, M. Awwad, S. Dukan, B. Vauzeilles, Angew. Chem. Int. Ed. 2012, 51, 3143, DOI: 10.1002/anie.201108127.

[9] M. A. Breidenbach, J. E. G. Gallagher, D. S. King, B. P. Smart, P. Wu, C. R. Bertozzi, Proc. Natl. Acad. Sci. USA 2010, 107, 3988, DOI: 10.1073/pnas.0911247107.

[10] C. Uttamapinant, A. Tangpeerachaikul, S. Grecian, S. Clarke, U. Singh, P. Slade, K. R. Gee, A. Y. Ting, Angew. Chem. Int. Ed. 2012, 51, 5852, DOI: $10.1002 /$ anie.201108181.

[11] J. A. Prescher, D. H. Dube, C. R. Bertozzi, Nature 2004, 430, 873, DOI: 10.1038/nature02791.
[12] J. A. Prescher, C. R. Bertozzi, Nat. Chem. Biol. 2005, 1, 13, DOI: 10.1038/nchembio0605-13.

[13] C. D. Spicer, T. Triemer, B. G. Davis, J. Am Chem. Soc. 2012, 134, 800, DOI: 10.1021/ ja209352s.

[14] N. Li, R. K. V. Lim, S. Edwardraja, Q. Lin, J. Am. Chem. Soc. 2011, 133, 15316, DOI: 10.1021/ja2066913.

[15] J. Wang, B. Cheng, J. Li, Z. Zhang, W. Hong, X Chen, P. R. Chen, Angew. Chem. Int. Ed. 2015, 54, 5364, DOI: 10.1002/anie.201409145.

[16] R. M. Yusop, A. Unciti-Broceta, E. M. Johansson, R. M. Sanchez-Martin, M. Bradley, Nat. Chem. 2011, 3, 239, DOI: 10.1038/ nchem.981.

[17] J. Li, J. Yu, J. Zhao, J. Wang, S. Zheng, S. Lin, L. Chen, M. Yang, S. Jia, X. Zhang, P. R. Chen, Nat. Chem. 2014, 6, 352, DOI: 10.1038/ nchem.1887.

[18] M. A. Miller, B. Askevold, H. Mikula, R. H. Kohler, D. Pirovich, R. Weissleder, Nat. Commun. 2017, 8, 15906, DOI: 10.1038/ncomms 15906.

[19] C. Streu, E. Meggers, Angew. Chem. Int. Ed. 2006, 45, 5645, DOI: 10.1002/anie.200601752.

[20] P. K. Sasmal, C. N. Streu, E. Meggers, Chem Commun. 2013, 49, 1581, DOI: 10.1039/ c2cc37832a.

[21] S. V. Chankeshwara, E. Indrigo, M. Bradley, Curr. Opin. Chem. Biol. 2014, 21, 128, DOI: 10.1016/j.cbpa.2014.07.007.

[22] M. Yang, J. Li, P. R. Chen, Chem. Soc. Rev. 2014, 43, 6511, DOI: 10.1039/C4CS00117F.

[23] T. Völker, E. Meggers, Curr. Opin. Chem. Biol. 2015, 25, 48, DOI: 10.1016/j.cbpa.2014.12.021.

[24] M. Jbara, S. K. Maity, A. Brik, Angew. Chem. Int. Ed. 2017, 56, 10644, DOI: 10.1002/ anie. 201702370

[25] M. Martínez-Calvo, J. L. Mascareñas, Coord. Chem. Rev. 2018, 359, 57, DOI: 10.1016/j. ccr.2018.01.011

[26] V. Hong, N. F. Steinmetz, M. Manchester, M. G Finn, Bioconjug. Chem. 2010, 21, 1912, DOI: 10.1021/bc100272z.

[27] A. J. Link, D. A. Tirrell, J. Am. Chem. Soc 2003, 125, 11164, DOI: 10.1021/ja036765z.

[28] A. J. Link, M. K. S. Vink, D. A. Tirrell, J. Am. Chem. Soc. 2004, 126, 10598, DOI: 10.1021/ ja047629c.

[29] K. E. Beatty, J. C. Liu, F. Xie, D. C. Dieterich, E. M. Schuman, Q. Wang, D. A. Tirrell, Angew. Chem. Int. Ed. 2006, 45, 7364, DOI: 10.1002/ anie. 200602114.

[30] M. Yang, Y. Song, M. Zhang, S. Lin, Z. Hao, Y. Liang, D. Zhang, P. R. Chen, Angew. Chem. Int. Ed. 2012, 51, 7674, DOI: 10.1002/ anie. 201204029

[31] M. Yang, A. S. Jalloh, W. Wei, J. Zhao, P. Wu, P. R. Chen, Nat. Commun. 2014, 5, 4981, DOI: 10.1038/ncomms5981

[32] S. Li, L. Wang, F. Yu, Z. Zhu, D. Shobaki, H. Chen, M. Wang, J. Wang, G. Qin, U. J. Erasquin, L. Ren, Y. Wang, C. Cai, Chem. Sci. 2017, 8, 2107, DOI: 10.1039/C6SC02297A.

[33] V. Bevilacqua, M. King, M. Chaumontet, M. Nothisen, S. Gabillet, D. Buisson, C. Puente, A. Wagner, F. Taran, Angew. Chem. Int. Ed. 2014, 53, 5872, DOI: 10.1002/anie.201310671.

[34] Y. Bai, X. Feng, H. Xing, Y. Xu, B. K. Kim, N. Baig, T. Zhou, A. A. Gewirth, Y. Lu, E. Oldfield, S. C. Zimmerman, J. Am. Chem. Soc. 2016, 138, 11077, DOI: 10.1021/jacs.6b04477.

[35] J. Clavadetscher, S. Hoffmann, A. Lilienkampf, L. Mackay, R. M. Yusop, S. A. Rider, J. J. Mullins, M. Bradley, Angew. Chem. Int. Ed. 2016, 55, 15662, DOI: 10.1002/ anie. 201609837

[36] J. Miguel-Ávila, M. Tomás-Gamasa, A. Olmos, P. J. Pérez, J. L. Mascareñas, Chem. Sci. 2018, 9, 1947, DOI: 10.1039/C7SC04643J.

[37] B. M. Trost, F. D. Toste, A. B. Pinkerton, Chem. Rev. 2001, 101, 2067, DOI: 10.1021/cr000666b.
[38] L. Zhang, X. Chen, P. Xue, H. H. Y. Sun, I. D. Williams, K. B. Sharpless, V. V. Fokin, G. Jia, J. Am. Chem. Soc. 2005, 127, 15998, DOI: 10.1021/ja054114s

[39] P. Destito, J. R. Couceiro, H. Faustino, F. López, J. L. Mascareñas, Angew. Chem. Int. Ed. 2017, 56, 10766, DOI: 10.1002/anie.201705006

[40] S. Ding, G. Jia, J. Sun, Angew. Chem. Int. Ed. 2014, 53, 1877, DOI: 10.1002/anie.201309855.

[41] Y. Liao, Q. Lu, G. Chen, Y. Yu, C. Li, X. Huang, ACS Catal. 2017, 7, 7529, DOI: 10.1021/ acscatal.7b02558.

[42] Z. Gao, V. Gouverneur, B. G. Davis, J. Am. Chem. Soc. 2013, 135, 13612, DOI: 10.1021/ ja4049114.

[43] J. Clavadetscher, E. Indrigo, S. V. Chankeshwara, A. Lilienkampf, M. Bradley, Angew. Chem. Int. Ed. 2017, 56, 6864, DOI: 10.1002/anie.201702404.

[44] E. Indrigo, J. Clavadetscher, S. V. Chankeshwara, A. Lilienkampf, M. Bradley, Chem. Commun. 2016, 52, 14212, DOI: 10.1039/C6CC08666G.

[45] F. Wang, Y. Zhang, Z. Du, J. Ren, X. Qu, Nat. Commun. 2018, 9, 1209, DOI: 10.1038/s41467018-03617-X

[46] R. K. V. Lim, N. Li, C. P. Ramil, Q. Lin, ACS Chem. Biol. 2014, 9, 2139, DOI: 10.1021/ cb500443x.

[47] N. Li, C. P. Ramil, R. K. V. Lim, Q. Lin, ACS Chem. Biol. 2015, 10, 379, DOI: 10.1021/ cb500649q.

[48] K. Tsubokura, K. K. H. Vong, A. R. Pradipta, A. Ogura, S. Urano, T. Tahara, S. Nozaki, H. Onoe, Y. Nakao, R. Sibgatullina, A. Kurbangalieva, Y. Watanabe, K. Tanaka, Angew. Chem. Int. Ed. 2017, 56, 3579, DOI: 10.1002/anie.201610273.

[49] D. J. Gorin, B. D. Sherry, F. D. Toste, Chem. Rev. 2008, 108, 3351, DOI: $10.1021 / \mathrm{cr} 068430 \mathrm{~g}$

[50] E. Jiménez-Núñez, A. M. Echavarren, Chem. Rev. 2008, 108, 3326, DOI: 10.1021/ cr0684319.

[51] A. Fürstner, E. Beckmann, B. J. Burke, A. Boyer, S. L. Maslen, S. V. Ley, L. Fensterbank, M. Malacria, D. J. Cárdenas, A. M. Echavarren, Chem. Soc. Rev. 2009, 38, 3208, DOI: 10.1039/ b816696j.

[52] A. Corma, A. Leyva-Pérez, M. J. Sabater, Chem. Rev. 2011, 111, 1657, DOI: 10.1021/ cr100414u.

[53] F. López, J. L. Mascareñas, Beilstein J. Org. Chem. 2013, 9, 2250, DOI: 10.3762/bjoc.9.264.

[54] J. L. Mascareñas, F. López, in 'Topics in Organometallic Chemistry', Springer, Cham, 2016, pp. 1, DOI: 10.1007/7081_2015 5006.

[55] J. Francos, F. Grande-Carmona, H. Faustino, J. Iglesias-Sigüienza, E. Díez, I. Alonso, R. Fernández, J. M. Lassaletta, F. López, J. L. Mascareñas, J. Am. Chem. Soc. 2012, 134, 14322, DOI: $10.1021 /$ ja3065446.

[56] I. Varela, H. Faustino, E. Díez, J. IglesiasSigüenza, F. Grande-Carmona, R. Fernández, J. M. Lassaletta, J. L. Mascareñas, F. López, ACS Catal. 2017, 7, 2397, DOI: 10.1021/ acscatal.6b03651.

[57] H. Faustino, I. Alonso, J. L. Mascareñas, F Lõpez, Angew. Chem. Int. Ed. 2013, 52, 6526, DOI: 10.1002/anie.201302713.

[58] J. H. Do, H. N. Kim, J. Yoon, J. S. Kim, H.-J. Kim, Org. Lett. 2010, 12, 932, DOI: 10.1021/ ol902860f.

[59] H. Seo, M. E. Jun, K. Ranganathan, K. H. Lee, K. T. Kim, W. Lim, Y. M. Rhee, K. H. Ahn, Org. Lett. 2014, 16, 1374, DOI: 10.1021/o15001389.

[60] C. Vidal, M. Tomás-Gamasa, P. Destito, F. López, J. L. Mascareñas, Nat. Commun. 2018, 9, 1913, DOI: 10.1038/s41467-018-04314-5.

[61] F. Schwizer, Y. Okamoto, T. Heinisch, Y. Gu, M. M. Pellizzoni, V. Lebrun, R. Reuter, V. Köhler, J. C. Lewis, T. R. Ward, Chem. Rev. 2018, 118 , 142, DOI: 10.1021/acs.chemrev.7b00014. 
[62] M. Jeschek, R. Reuter, T. Heinisch, C. Trindler, J. Klehr, S. Panke, T. R. Ward, Nature 2016, 537, 661, DOI: 10.1038/nature19114.

[63] O. Vázquez, M. I. Sánchez, J. Martínez-Costas, M. E. Vázquez, J. L. Mascareñas, Org. Lett. 2010, 12, 216, DOI: 10.1021/o1902501j.

[64] M. I. Sánchez, C. Penas, M. E. Vázquez, J. L. Mascareñas, Chem. Sci. 2014, 5, 1901, DOI: 10.1039/c3sc53317d.

[65] P. K. Sasmal, S. Carregal-Romero, W. J. Parak, E. Meggers, Organometallics 2012, 31, 5968, DOI: 10.1021/om3001668.

[66] S. Tanaka, H. Saburi, Y. Ishibashi, M. Kitamura, Org. Lett. 2004, 6, 1873, DOI: 10.1021/ ol0493397.

[67] H. Saburi, S. Tanaka, M. Kitamura, Angew. Chem. Int. Ed. 2005, 44, 1730, DOI: $10.1002 /$ anie. 200462513

[68] T. Völker, F. Dempwolff, P. L. Graumann, E. Meggers, Angew. Chem. Int. Ed. 2014, 53, 10536, DOI: 10.1002/anie.201404547.

[69] M. Tomás-Gamasa, M. Martínez-Calvo, J. R. J. R. Couceiro, J. L. Mascareñas, Nat. Commun 2016, 7, 12538, DOI: 10.1038/ncomms 12538 .

[70] T. Völker, E. Meggers, ChemBioChem 2017, 18, 1083, DOI: 10.1002/cbic.201700168.

[71] M. Martínez-Calvo, J. R. Couceiro, P. Destito, J. Rodriguez, J. Mosquera, J. L. Mascareñas, ACS Catal. 2018, 8, 6055, DOI: 10.1021/ acscatal.8b01606.

[72] E. Indrigo, J. Clavadetscher, S. V. Chankeshwara, A. Megia-Fernandez, A. Lilienkampf, M. Bradley, L. Chen, M. Yang, S. Jia, X. Zhang,
P. R. Chen, Chem. Commun. 2017, 278, 31192 , DOI: $10.1039 / \mathrm{C} 7 \mathrm{CC} 02988 \mathrm{H}$

[73] B. Stenton, B. Oliveira, M. Matos, L. Sinatra, G. J. L. Bernardes, Chem. Sci. 2018, DOI: $10.1039 / \mathrm{C} 8 \mathrm{SC} 00256 \mathrm{H}$

[74] J. T. Weiss, J. C. Dawson, K. G. Macleod, W. Rybski, C. Fraser, C. Torres-Sánchez, E. E. Patton, M. Bradley, N. O. Carragher, A. UncitiBroceta, Nat. Commun. 2014, 5, 3277, DOI: 10.1038/ncomms4277.

[75] A. M. Pérez-López, B. Rubio-Ruiz, V. Sebastián, L. Hamilton, C. Adam, T. L. Bray, S. Irusta, P. M. Brennan, G. Lloyd-Jones, D. Sieger, J. Santamaría, A. Unciti-Broceta, Angew. Chem. Int. Ed. 2017, 56, 12548, DOI: 10.1002/anie.201705609.

[76] J. Wang, S. Zheng, Y. Liu, Z. Zhang, Z. Lin, J. Li, G. Zhang, X. Wang, J. Li, P. R. Chen, J. Am. Chem. Soc. 2016, 138, 15118, DOI: 10.1021/ jacs.6b08933.

[77] G. Sava, A. Bergamo, P. J. Dyson, Dalton Trans. 2011, 40, 9069, DOI: 10.1039/c1dt10522a.

[78] S. J. Dougan, A. Habtemariam, S. E. McHale, S. Parsons, P. J. Sadler, Proc. Natl. Acad. Sci. USA 2008, 105, 11628, DOI: 10.1073/ pnas.0800076105.

[79] J. J. Soldevila-Barreda, I. Romero-Canelón, A. Habtemariam, P. J. Sadler, Nat. Commun. 2015, 6, 6582, DOI: $10.1038 /$ ncomms 7582 .

[80] J. P. C. Coverdale, I. Romero-Canelón, C. Sanchez-Cano, G. J. Clarkson, A. Habtemariam, M. Wills, P. J. Sadler, Nat. Chem. 2018, 10, 347 , DOI: $10.1038 /$ nchem.2918.
[81] K. K. Sadhu, E. Lindberg, N. Winssinger, J Wang, S. Q. Zheng, S. X. Lin, L. Chen, M. Y. Yang, S. Jia, X. Y. Zhang, P. R. Chen, Chem. Commun. 2015, 51, 16664, DOI: 10.1039/ C5CC05405B.

[82] L. Holtzer, I. Oleinich, M. Anzola, E. Lindberg, K. K. Sadhu, M. Gonzalez-Gaitan, N Winssinger, ACS Cent. Sci. 2016, 2, 394, DOI: 10.1021/acscentsci.6b00054.

[83] Z. Liu, A. Habtemariam, A. M. Pizarro, S. A Fletcher, A. Kisova, O. Vrana, L. Salassa, P. C. A. Bruijnincx, G. J. Clarkson, V. Brabec, P. J. Sadler, J. Med. Chem. 2011, 54, 3011, DOI: $10.1021 /$ jm2000932.

[84] Z. Liu, A. Habtemariam, A. M. Pizarro, G. J. Clarkson, P. J. Sadler, Organometallics 2011, 30, 4702, DOI: 10.1021/om2005468.

[85] Z. Liu, I. Romero-Canelón, B. Qamar, J. M. Hearn, A. Habtemariam, N. P. E. Barry, A. M. Pizarro, G. J. Clarkson, P. J. Sadler, Angew. Chem. Int. Ed. 2014, 53, 3941, DOI: 10.1002/ anie. 201311161.

[86] S. Bose, A. H. Ngo, L. H. Do, J. Am. Chem. Soc. 2017, 139, 8792, DOI: 10.1021/jacs.7b03872.

[87] A. H. Ngo, M. Ibañez, L. H. Do, ACS Catal. 2016, 6, 2637, DOI: 10.1021 /acscatal.6b00395.

[88] P. K. Sasmal, S. Carregal-Romero, A. A Han, C. N. Streu, Z. Lin, K. Namikawa, S. L. Elliott, R. W. Köster, W. J. Parak, E. Meggers, ChemBioChem 2012, 13, 1116, DOI: 10.1002/ cbic. 201100719 . 